\title{
Piracy versus Netflix: Subscription Video on Demand Dissatisfaction as an Antecedent of Piracy
}

\author{
Janne Riekkinen \\ University of Jyväskylä \\ janne.p.h.riekkinen@jyu.fi
}

\begin{abstract}
Drawing from cognitive dissonance and neutralization theories, this study seeks to improve the understanding on consumer decision-making between the current legal and illegal video consumption alternatives. We develop and test a research model featuring Subscription Video on Demand (SVOD) satisfaction and various dimensions of SVOD quality as antecedents of video piracy neutralizations and attitudes. Based on results from an online survey among Finnish SVOD users, SVOD satisfaction is primarily determined by content quality, and has a small negative effect on attitude toward piracy through decreased piracy neutralization. However, it appears that current legal services are not seen as true alternatives to illegal sources of video content.
\end{abstract}

\section{Introduction}

The rise of Subscription Video on Demand (SVOD) services has shaped the landscape in entertainment and media industries during the 2010's. However, pirates are still well and alive, and continue to affect the businesses. While there are indications of decline in music piracy [1] concurrent with growth and expansion in paid music streaming, the same trend has not been observed in the case of video content. Despite the success of Netflix and others, the rise of SVOD has not managed to thwart online piracy; instead, piracy traffic numbers for movies and series have continued to rise at the same time, with new episodes and seasons of shows such as Game of Thrones continually making headlines by breaking previous piracy traffic records.

Online video piracy has many similarities, but also certain differences with music piracy. Both typically take place in peer-to-peer networks and have been subjects to similar campaigns from the rights holders and industry organizations. In the past, Internet connection speeds limited the viability of video piracy, as the pirated video files were either too large or of considerably lower quality than legal copies. Later, with increased connection speeds and storage capacities, video piracy has become practically as convenient as music piracy. However, compared to music, the legal availability of video content is not as broad as it is with music, as SVOD services have selected strategies leaning on exclusive content, opposed to larger and more generic catalogues of music streaming services such as Spotify and Deezer.

Various papers have examined the interplay and consumer decisions between legal and illegal music options [2-5], but recent developments also call for more research on video content from the consumer perspective. The objective of this study is to respond to this need by exploring the antecedents of video piracy, especially those related to perceptions of legal SVOD services. We will address the following question: Do the merits of SVOD services and SVOD satisfaction shape video piracy attitudes and behaviors, and through which mechanisms?

Our research model deals with digital video piracy in a market where legal SVOD options are present. The availability of various legal options with different offers complicates the decisions made by the consumers. Within our example setting of a SVOD market in a Northern European country, we identify unique qualities of digital video consumption, and address them by including contextualized inputs from neutralization theory [6], cognitive dissonance theory [7], and expectation-confirmation theory $[8,9]$.

\section{Theoretical background}

The general-level reasoned action framework from social psychology (i.e., Theory of Reasoned Action, TRA, Theory of Planned Behavior, TPB, and their further developments) [10-12] has become the most common theoretical approach to individual-level consumer piracy questions within many disciplines. This is also evident from Lowry, Zhang and Wu's meta-analysis of empirical piracy studies [13]. However, in their basic form, TRA and TPB neglect the normative and moral aspects which are crucial to 
this context, and have been consequently extended with constructs such as moral obligation [14], or with broader ethics theories [15].

Many piracy researchers have adopted neutralization theory to provide an alternative viewpoint, but the contributions of cognitive dissonance have been scarcer [16]. These two theories have potential to complement each other in many ways $[17,18]$, so it would be useful to consider their impacts from an integrated perspective. Considering the current SVOD market alternatives to piracy, customer satisfaction perspective is equally important. To this end, we also will utilize inputs from expectationconfirmation research, which is another popular theme within marketing and information systems research that has drawn from cognitive dissonance.

\subsection{Neutralization theory in digital piracy research}

Neutralization theory (NT) originates from criminology, where it was proposed Sykes and Matza [6] to address juvenile delinquency. The assumption underlying NT is that deep down, the delinquent have the same values as the law-abiding general public. They employ verbal and mental techniques to lessen the guilt associated with societal value and rule violations. These are called neutralization techniques.

In their article, Sykes and Matza distinguished five of these: denial of responsibility, denial of injury, denial of the victim, condemnation of condemners and appeal to higher loyalties. Subsequent research has identified many additional techniques, such as metaphor of the ledger, defense of necessity, and justification by comparison [19]. It is important to note that neutralizations themselves may not necessarily be the root cause of offending, but a mechanism that allows offending to continue. For a more comprehensive look on NT that goes beyond individual technique issues, see Maruna and Copes' [20] review.

The theory has appeared lucrative to many digital piracy researchers, because online pirates are typically viewed as rather normal young individuals who accept general societal values, and thus have greater potential for guilt than hardened career criminals. In criminology literature, e.g., Ingram and Hinduja [21] and Morris and Higgins [22] have employed NT in quantitative studies concerning music and media piracy. There is also some longitudinal evidence that the level of neutralization affects actually occurring music piracy [23]. Within the IS discipline, Siponen, Vance, and Willison [24] found that the techniques condemnation of the condemners and appeal to higher loyalties predict software piracy intentions.
Because of the considerable breadth of current piracy research, applications of NT have suffered from a certain lack of conceptual clarity. It is also of note that some piracy researchers have employed the theory, but have dubbed the construct as "rationalization", [25,26] which has post-behavior connotations, although neutralization was originally perceived as both preceding and following criminal behavior [6]. Unlike cognitive dissonance theory that deals solely with post-behavior reasoning, NT takes a sequential view on deviance: neutralization can be both a cause and an effect of behavior [17].

\subsection{Cognitive dissonance and confirmation of expectations}

Festinger's [7] theory of cognitive dissonance (CDT) is one of the most influential theories in social psychology [27]. It is based on an everyday observation about humans' dislike toward inconsistency. For example, illegal downloading of copyrighted material creates conflicts with the laws and values of the society, which need to be solved. Here, the cognition of one's online piracy participation and the cognition about the inappropriateness of online piracy are said to be dissonant with each other. When such conflict is recognized, dissonance arousal takes place, and the need reduce dissonance follows. Dissonance reduction can happen by either, 1) changing one of the dissonant elements, such as attitude or behavior, 2) adding consonant cognitions to increase the overall consonance between elements, or 3 ) decreasing the importance of dissonant elements.

The concept of cognitive dissonance is somewhat deceptively named, because various separate elements of dissonance exist: e.g., Hausknecht et al. [28] discern distinct cognitive, emotional and behavioral components of dissonance. In our case, the cognitive component is the person's recognition that beliefs about piracy are inconsistent with piracy behavior. The emotional component represents dissonance as a psychologically uncomfortable state [28]. Compared to reasoned action studies [14], this concept largely overlaps with moral obligation, which is commonly defined as feelings of guilt.

Sequentially, the cognition about inconsistent beliefs or actions instigates the dissonance process, and psychological discomfort follows. Available dissonance reduction mechanisms are then applied. These represent the third, behavioral dimension of dissonance [28]. In our framework, we equate this element of dissonance with neutralization techniques, because there are notable connections between the theories. In their review of NT, Maruna and Copes [20] 
propose that integration with CDT would be "an important starting point" in refining NT. Like NT, CDT predicts that the individual will seek to neutralize the cognition through variety of excuses and justifications, and as in CDT, the primary motivation behind neutralization is establishing internal consistency [20]. Odou and Bonnin [17] describe neutralization as an addition of a discursive space, or an area of tolerance around the norms. Interpreted through the lens of CDT, neutralizations function either by adding consonant elements (such as the technique of "appeal to higher loyalties") or by decreasing the importance of dissonant elements (such as "claim of normalcy") [18].

Expectation-confirmation theory (ECT) [8,29] has found an important position in information systems literature in the IS continuance context. According to Bhattacherjee [9], IS continuance intention is primarily determined by the user's satisfaction with prior IS use. In turn, satisfaction is determined by expectation of the IS and confirmation of expectation following actual use. In the IS continuance model, expectations are represented by a construct drawn from the Technology Acceptance Model (TAM) [30], perceived usefulness (PU), and similarly following TAM, a link is hypothesized between PU and continuance intention. On the grounds of CDT, confirmation has an impact on PU: users' prior usefulness perceptions tend to elevate when they are exceeded and decrease when they are not met, because in order to reduce cognitive dissonance, rational users will modify their usefulness perceptions to be more consistent with reality.

However, we note that TAM and its perceived usefulness construct were created in a general organizational IS use context, and that they do not capture any specific service level issues. Thus, we do not believe that this conceptualization provides sufficient theoretical depth in the case of video streaming. To address this, we first identify the perceived merits, or lack thereof, of SVOD services in the case of an example market of Finland, a Northern European country.

\section{Research model}

Our research model can be divided into two parts: the first concerns to the facets of perceived SVOD service quality (content, system, and security) as an antecedent of satisfaction, and the other concerns to the effects of satisfaction on perceptions of about piracy options. The theoretical model is presented in Figure 1.

\subsection{The SVOD service quality and satisfaction}

During the study's time frame, independent "overthe-top" SVOD providers in our example market Finland included the American companies Netflix and HBO (branded HBO Nordic), and the Swedish-owned Viaplay and $\mathrm{C}$ More. In addition, the local Internet service providers provided access to broader and more customizable services, which included bundled live IPTV broadcasts from cable channels, movie rentals, services from the aforementioned SVOD providers, and music streaming services.

The purpose of SVOD services is to provide consumers full access to a certain limited catalogue of video content, which includes the same titles for all customers in a given market. Thus, the primary merits of SVOD services are related to content quality. Following Shin [31,32], we also consider other dimensions of perceived quality to be relevant for SVOD services: system quality and security.

Content quality. As the novelty of the narrative is integral to enjoyment, video titles require far more time and attention from consumers, and typically have less replay value in comparison to music. For SVOD services, this emphasizes the constant need for catalogue updates. Compared to music subscription services with tens of millions of titles, SVOD services are noticeably narrow and more exclusive in their scope, because the markets operate with different logics in terms of monetization and intellectual property rights. Production of individual video titles is also far more expensive in comparison to music.

The market leader Netflix has given up many major Hollywood titles and directed its efforts toward exclusive and original productions (e.g., House of Cards) not legally available anywhere else. The competitor $\mathrm{HBO}$ has a long history with a similar strategy. This trend towards high quality exclusive programming creates a need to subscribe to multiple SVOD services in case the consumer wants access to larger catalogues, and even then, it is very possible that the particular titles sought by the consumers are simply not legally available for streaming for them. Exclusivity is likely to promote piracy, as has also been observed in the music context with piracy numbers of individual exclusive albums [33].

Hypothesis 1a: Perceived SVOD Content Quality positively influences SVOD Satisfaction.

System quality. Even if the content catalogue is of high quality, and the interactions are well designed, the underlying technical-level system quality needs to be in order as well [34]. System quality commonly manifests in such general qualities as accessibility, reliability, and response time [35].

The key qualities of audio-visual content are the qualities of the audio and video streams. To guarantee these, SVOD services generate a large amount of 
Internet traffic, and need reasonable connection speeds and computing power to make it possible to stream high definition content uninterrupted, and even more so in the case of more advanced standards of the future. Broad device support is important, because these services are often accessed through different devices, such as desktop and laptop computers, tablets, smartphones, gaming consoles and smart TV systems. Additional technical feature requirements include, e.g., options for subtitles in multiple languages, and a possibility to easily continue watching from the previous point where watching was interrupted.

Hypothesis 1b: Perceived SVOD System Quality positively influences SVOD Satisfaction.

Security. Finally, concerns about security frequently accompany IS use, especially when personal information and payments are involved. SVOD services incur monetary costs, and the accompanying transactions and storage of personal information should be perceived as secure. The study by Shin [32] highlights the effect of perceived security on IPTV usage intention, and we expect that security will also play a role in the rather similar SVOD context.

Hypothesis 1c: Perceived SVOD Security positively influences SVOD Satisfaction.

\subsection{Are dissatisfied SVOD customers tempted to turn to piracy?}

Empirical evidence supports the oft-repeated notion that lack of good legal services has made consumers turn to illegal alternatives [36]. With Netflix, HBO and others, the consumer has now been presented with legal SVOD options in addition to the previous pirate source options. As time goes on and the consumer accumulates actual use experiences, they will be able to properly review them in terms of their expectations, and considering the incurred costs. If the expectations are met or exceeded, the consumer is likely to be more or less satisfied with the service, and will likely continue its use.
Hypothesis 2: SVOD Satisfaction positively influences SVOD Continuance Intention.

In the case where a consumer selects a product or service out of multiple competing ones, CDT under the "free choice" paradigm [37] points towards immediate post-choice inflation of attitude towards the chosen option, and deflation of attitude towards the unchosen options in an effort to validate the choice. A key proposition derived from the cognitive dissonance and expectation-confirmation theories is thus that satisfied users will decrease their valuation of the illegal piracy option in comparison to legal SVOD option. This translates to more a negative attitude toward piracy (which we considered as a person's overall evaluation of performing piracy). Conversely, dissatisfied users would be likely to view piracy more positively.

The above goes hand in hand with another hypothesis. When SVOD dissatisfaction promotes propiracy attitudes, it also leads to a potential violation of the legal and societal norm of anti-piracy. This norm violation can be a cause of dissonance if identified. As a dissonance reduction mechanism, additional modifications to the relevant set of cognitions are needed. The level of agreement with piracy neutralizing sentiments is therefore expected to rise with dissatisfaction, and vice versa.

Hypothesis 3a: SVOD Satisfaction negatively influences Attitude toward Piracy.

Hypothesis 3b: SVOD Satisfaction negatively influences Piracy Neutralization.

As is evident from prior research, neutralizations and attitudes are very closely linked. From early on, attitude change has been considered as a sign of dissonance reduction in the cognitive dissonance literature [27]. As mentioned earlier, as mechanisms of dissonance reduction, neutralization techniques are employed to establish internal consistency [20]. Thus, neutralizations designed to create tolerance around piracy should result in more positive attitudes towards piracy.

Hypothesis 4: Piracy Neutralization positively influences Attitude toward Piracy.

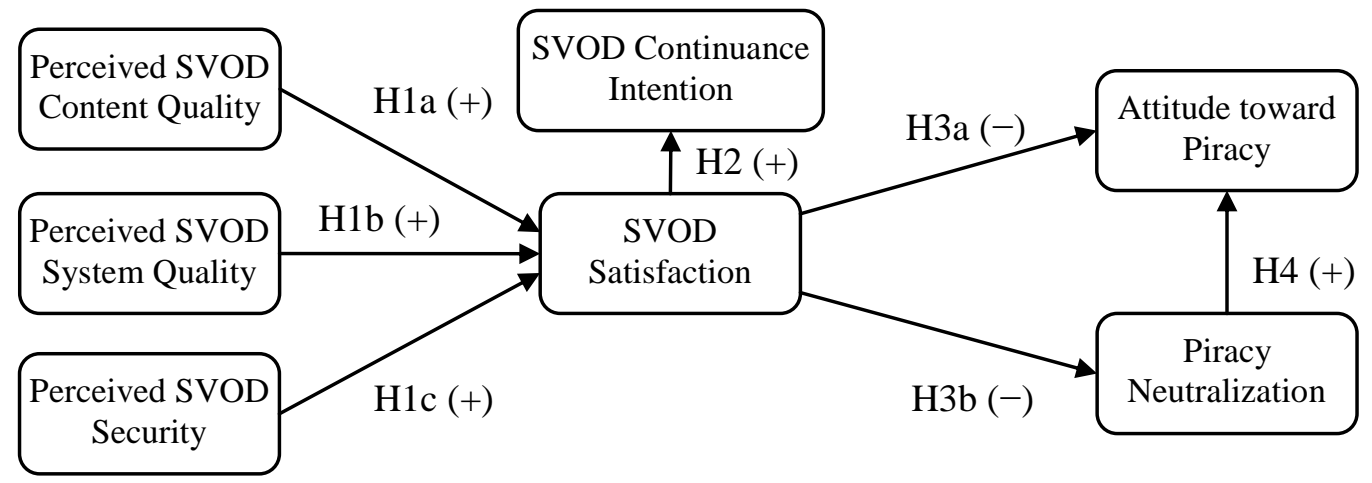

Figure 1. The theoretical model of SVOD perceptions as antecedents of piracy perceptions. 


\section{Methods and results}

We collected data from Finnish SVOD users via a self-administered online survey carried out during winter and spring 2017. For a pilot test, a link to the survey and an introductory promotional message was first posted to select discussion forums of varying audiences, and to a mailing list of one student organization of our university. In the primary study phase, the survey was promoted through our university's mailing lists for students, staff, and faculty, as well as the university website. We also advertised the study in social media outlets such as Facebook and Twitter. In the introductory message, it was mentioned that ten movie tickets would be raffled among the respondent. We received 153 completed responses out of 243 overall.

After dropping out respondents who took the survey but had not used paid SVOD services, we arrived at 124 responses, which we used as our sample to test the model. Out of these, $69(55.6 \%)$ were female, 50 male $(40.3 \%)$, and the remaining five (4.0\%) chose not to disclose or specify their gender. Average and median years of birth were 1986 (i.e., age 30-31 during the data collection) and 1989 (27-28). Students comprised the largest socioeconomic group in the sample (53.2\%, 66 respondents), followed by those who classified themselves as employed $(38.7 \%, 46)$.

The respondents were instructed to answer to all of the SVOD quality, security and satisfaction questions in relation to the service they themselves indicated as their primarily used service. They were instructed to indicate one, even if they had quit SVOD use for the time being. For the large majority of respondents (94), this was Netflix. On average, the respondents claimed to watch 1 hour and 19 minutes of SVOD content per day, from all services combined. Here, 15 respondents provided an answer of zero, indicating that they were at least currently inactive, if had not quit completely.

We employed covariance-based structural equation modelling with Mplus 7.11 software. We applied Anderson and Gerbing's [38] two-step approach. First, we specified a measurement model in the confirmatory factor analysis framework. Then, we specified a structural regression model based on our hypotheses, and followed with further models with different constraints, and compared the models sequentially.

\subsection{Variables}

The measured used in this study were presented in two different pages of the online survey, the first regarding SVOD service use and perceptions, and the second regarding piracy perceptions. Item order within question blocks was randomized for each respondent in an attempt to reduce the potential method biases arising automatic responding, and from the tendency to interpret similar items as identical. Some reverse-coded items were also included for control purposes. Whenever we detected that the questions could be difficult to understand, we included clarifications and cues alongside the question.

For most of our constructs, we used five-point Likert-style items anchored " 1 = fully disagree" and "5 = fully agree", with an extra option for "don't know / cannot say". The exception was Attitude toward Piracy (ATT), which we measured with four five-point semantic differential adjective pairs, such as good-bad, in the style of Fishbein and Ajzen [12].

For Piracy neutralization (NEUT), we employed a 10 -item scale consisting of items drawn from prior neutralization literature $[18,24,39,40] \quad-$ again rewording to them to refer to relevant aspects to video piracy instead of those of their original scope.

SVOD Continuance Intention (CIN) was derived from intention measures commonly used in TRA and TPB questionnaires [12], and were worded in terms of continuing to use SVOD services for the next two months (e.g., "I intend to continue using the SVOD service for the next two months").

Our SVOD Satisfaction (SAT) scale was derived from Bhattacherjee [9], and consisted of three items worded "I am very satisfied / pleased / delighted with the VOD service" (we constantly referred to the acronym 'VOD' in our items, because we expected it to be widely known among the target audience; we also specified that we meant paid services and provided examples). The difference was, however, that we used five-point Likert-style items instead of the semantic differential scale.

For Perceived SVOD Content Quality (CQ), we drew two of our items from Shin [31], and reworded them to better reflect SVOD context: "The content I can get from the SVOD service is valuable", and "The SVOD service provides content I want". To supplement our measurement, we generated three original items designed to capture features specific to SVOD service content catalogues relation to their enjoyableness, interestingness, and freshness, and included these in the survey alongside other items.

For Perceived SVOD System Quality (SQ), we used the three "perceived system quality" items from [31], which constitute the effectively identical scale dubbed as "perceived quality of service" in [32]. Again, we supplemented the scale with four original items designed to capture important SVOD features such as picture quality, sound quality, playback smoothness, and device support. 
Finally, for Perceived SVOD Security (SE), we used the three-item measure from [32].

As our sample included individuals with varying piracy backgrounds, we used the dummy of "currently active piracy" (ACPIR; $1=$ active, $0=$ not active) as a control variable. This dummy variable was created from respondents' answers' to questions about had they ever downloaded or streamed videos illegally, and if yes, currently how frequently. We believed this to be appropriate, because attachment to piracy will shape how piracy is perceived. Past piracy is also a potent predictor of future piracy behavior $[13,14]$. Out of our current SVOD user sample, $44 \%$ indicated themselves as active pirates.

The full list of items and their correlation matrix are omitted here to save space, but are available upon request from the authors.

\subsection{Measurement model}

First, we explored our measurement items by examining their correlation matrix for unusual correlations. We identified SAT3 correlating more strongly with measures of CIN than those of SAT, and decided to drop the item as unrepresentative of the SAT construct. We also eliminated one security item (SE3) based on large amount of missing values indicating that the item was difficult to understand before proceeding with the analysis. Both of the above cases could be explained by slight connotative differences introduced when translating items from English to Finnish.

Based on these scales, we specified an initial measurement model, where the factors are allowed to correlate with each other (confirmatory factor analysis, CFA). As with all subsequent models, we estimated this model using robust maximum likelihood (MLR), and handled missing data with the default Mplus option, full information maximum likelihood (FIML). The initial model had insufficient fit with the data, $\chi^{2}=$ 802.674 (500), $\mathrm{p}=0.000, \mathrm{CFI}=0.871$. As our sample size $(n=124)$ was rather small, and many of our scales rather long at 5-10 items each, we proceeded to eliminate items with weaker loadings to their intended constructs in an effort to find a more parsimonious and better-fitting model. Out of the 10-item neutralization scale, we selected five items bases on loadings while still aiming to capture multiple techniques of neutralization in the scale.

The purged CFA model (which we designated as Model 1) fit the data better: $\chi^{2}=314.784$ (225), $\mathrm{p}=$ $0.000, \mathrm{CFI}=0.946, \mathrm{RMSEA}=0.057, \mathrm{SRMR}=0.062$. Composite reliability coefficients ranged from 0.722 to 0.987. All the constructs met Fornell and Larcker's [41] convergent validity criteria, average variance explained (AVE) exceeding 0.50, and the discriminant validity criteria, the square root of AVE's for each construct exceeding the correlations with the other constructs in the model (Table 1). Thus, we deemed the model satisfactory in terms of both convergent and discriminant validity.

In addition to taking a priori procedural steps to minimize potential common method bias, we also undertook Harman's single-factor test, and found that $31.1 \%$ of variance was captured by a single factor in an exploratory factor analysis. Despite this test is often considered to be insensitive [42], a recent simulation study found that with typical scale reliabilities, the test fails to detect upward CMB in causal relationships only when common method variance approaches $70 \%$ or more [43]. This magnitude is very unlikely to be found in typical surveys, and would likely also manifest as other serious problems with construct validity [43].

Table 1. Latent construct correlations (Model 1). On-diagonal values (in bold) are square roots of AVE. CR = composite reliability, AVE = average variance extracted. Note: ACPIR is a single-

\begin{tabular}{|l||l|l|l|l|l|l|l|l|l|l|}
\hline $\begin{array}{l}\text { Construct } \\
\text { (\# of items) }\end{array}$ & CR & AVE & CQ & SQ & SE & SAT & CIN & ATT & NEUT & ACPIR \\
\hline CQ (3) & 0.817 & 0.603 & $\mathbf{0 . 7 7 7}$ & & & & & & & \\
\hline SQ (4) & 0.854 & 0.597 & 0.476 & $\mathbf{0 . 7 7 3}$ & & & & & & \\
\hline SE (2) & 0.722 & 0.566 & 0.340 & 0.706 & $\mathbf{0 . 7 5 2}$ & & & & & \\
\hline SAT (2) & 0.764 & 0.618 & 0.741 & 0.738 & 0.606 & $\mathbf{0 . 7 8 6}$ & & & & \\
\hline CIN (3) & 0.987 & 0.961 & 0.396 & 0.347 & 0.324 & 0.519 & $\mathbf{0 . 9 8 0}$ & & & \\
\hline ATT (4) & 0.927 & 0.761 & -0.073 & -0.160 & -0.111 & 0.093 & -0.171 & $\mathbf{0 . 8 7 2}$ & & \\
\hline NEUT (5) & 0.858 & 0.551 & -0.279 & -0.197 & -0.372 & -0.057 & -0.283 & 0.519 & $\mathbf{0 . 7 4 2}$ & \\
\hline ACPIR (1) & 1.000 & 1.000 & 0.066 & 0.021 & 0.055 & 0.231 & 0.036 & 0.340 & 0.328 & $\mathbf{1 . 0 0 0}$ \\
\hline
\end{tabular}




\subsection{Structural model}

For our theoretical structural model (Model 2), we replaced the correlations between factors with directed paths based on our hypotheses. The dummy variable of active piracy participation was included as a control for each dependent variable. The exogenous variables SF, SQ, SE, and ACPIR were still allowed to correlate with each other, as well as the error terms of otherwise unrelated ultimate outcome variables ATT and CIN. The theoretical model had a reasonable fit with the data, $\chi^{2}=334.792(235), p=0.000$, CFI $=0.940$, RMSEA $=0.059$, SRMR 0.073.

As Anderson \& Gerbing [38] recommend, one should compare the theoretical model to two other models: the next-best-constrained (Model 3) and the next-best-unconstrained (Model 4) models. For the next-best-constrained model, we constrained the hypothesized path from SAT to ATT to zero, because the consumers may not associate legal and illegal forms of video content consumption with each other as equal alternatives. We also uncorrelated the error terms of ATT and CIN. For the next-best-unconstrained model, we added two paths from CIN to ATT and NEUT to check if the effects of SVOD satisfaction on these antecedents of piracy are mediated by the intention to continue using SVOD.

First, we proceeded to compare the theoretical model (Model 2) to the next-best-constrained model (Model 3). Because the models were estimated with the MLR estimator, we employed Satorra and Bentlers' [44] correction formula for $\chi^{2}$ difference tests. In this comparison, Model 3 gained two degrees of freedom with the change of 0.581 in $\chi^{2}$, a statistically nonsignificant increase $(\mathrm{p}=0.748)$. Thus we preferred Model 3. We then went on to compare Model 3 to Model 4. With a loss of three degrees of freedom, $\chi^{2}$ changed by a statistically nonsignificant $-2.580(\mathrm{p}=$ 0.461). Thus, we still preferred Model 3.

Based on modification indices, we included the theoretically plausible correlation between the error terms of the same construct's indicators: ATT4 and ATT2 (M.I. = 39.489). With this addition, we arrived at our best model (Model 5: $\chi^{2}=299.120$ (236), $\mathrm{p}=$ $0.003, \mathrm{CFI}=0.962, \mathrm{RMSEA}=0.046, \mathrm{SRMR}=0.075$; vs Model 3: $\Delta \chi^{2}=-136.424, \Delta \mathrm{df}=-1, \mathrm{p}=0.000$.
Further, we diagnosed the standardized residuals for the best model, and found that the largest sources of remaining misfit between the data and the model were the residual correlations of SAT2 with NEUT9 (4.291) and SQ3 with NEUT6 (4.267). In total, 25 out of 300 standardized residuals had absolute values over 1.96.

\subsection{Hypothesis test results}

Regarding hypotheses, the results of our theoretical and best models were very similar (Table 2), indicating that the results were robust. The following numbers are based on the best model.

Hypotheses $1 \mathrm{a}, 1 \mathrm{~b}$, and $1 \mathrm{c}$ predicted that perceived content quality, perceived system quality and perceived security would positively affect SVOD satisfaction. For 1a (perceived content quality), this was supported, $\beta=0.513, p=0.000$. Hypotheses $1 b$ (perceived system quality: $\beta=0.349, \mathrm{p}=0.129$ ) and $1 \mathrm{c}$ (perceived security: $\beta=0.200, p=0.311$ ) were not supported. This confirmed our expectation that contents are the most important factor for SVOD services, while system quality and security are secondary.

Hypothesis 2 predicted that SVOD satisfaction would lead to higher intention to continue using the SVOD service. The hypothesis was clearly supported, $\beta=0.520, p=0.000$.

Hypothesis 3a predicted that SVOD satisfaction would decrease the attitudes toward piracy. As our theoretical model results indicated that this effect was practically zero $(\beta=0.032, p=0.809)$, we omitted the path from our best model. Thus, the hypothesis was not supported. The related Hypothesis $3 \mathrm{~b}$ predicted that SVOD satisfaction would be negatively associated with piracy neutralization. The parameter estimate was negative and statistically significant at $\beta=-0.274, \mathrm{p}=$ 0.043 . Thus, the hypothesis was supported.

Hypothesis 4 predicted that piracy neutralization would lead to a more positive attitude toward piracy. This hypothesis was clearly supported, $\beta=0.498, \mathrm{p}=$ 0.000 . Along with ACPIR, neutralization accounted for $35 \%$ of variance in ATT. Finally, the indirect effect of SVOD satisfaction on attitude toward piracy through piracy neutralization $(\mathrm{H} 3 b * \mathrm{H} 4)$ was quite weak at $\beta=$ $-0.136, \mathrm{p}=0.038$.

Table 2. Theoretical and Best model results. ${ }^{* * *} p<0.001,{ }^{* *} p<0.01,{ }^{*} p<0.05,{ }^{\dagger} p<0.10$.

\begin{tabular}{|l||l|l||l|}
\hline \multicolumn{1}{|l|}{} & \multicolumn{2}{|l||}{ Standardized Model Estimates (S.E.) } & \\
& Model 2 - Theoretical & Model 5 - Best & Conclusions / Explanations \\
\hline \hline $\mathrm{CQ} \rightarrow \mathrm{SAT}(\mathrm{H} 1 \mathrm{a}+)$ & $0.514(0.140)^{* * * *}$ & $0.513(0.140)^{* * * *}$ & Hypothesis supported \\
\hline $\mathrm{SQ} \rightarrow \mathrm{SAT}(\mathrm{H} 1 \mathrm{~b}+)$ & $0.343(0.234)$ & $0.349(0.230)$ & Hypothesis not supported \\
\hline $\mathrm{SE} \rightarrow \mathrm{SAT}(\mathrm{H} 1 \mathrm{c}+)$ & $0.203(0.199)$ & $0.200(0.197)$ & Hypothesis not supported \\
\hline $\mathrm{SAT} \rightarrow \mathrm{CIN}(\mathrm{H} 2+)$ & $0.536(0.075)^{* * *}$ & $0.536(0.074)^{* * *}$ & Hypothesis supported \\
\hline $\mathrm{SAT} \rightarrow \mathrm{ATT}(\mathrm{H} 3 \mathrm{a}-)$ & $0.032(0.134)$ & 0 (fixed) & Hypothesis not supported \\
\hline
\end{tabular}




\begin{tabular}{|c|c|c|c|}
\hline SAT $\rightarrow$ NEUT $(\mathrm{H} 3 \mathrm{~b}-)$ & $-0.277(0.139)^{*}$ & $-0.274(0.135)^{*}$ & Hypothesis supported \\
\hline NEUT $\rightarrow$ ATT $(\mathrm{H} 4+)$ & $0.460(0.122)^{* * *}$ & $0.498(0.112)^{* * *}$ & Hypothesis supported \\
\hline ACPIR $\rightarrow$ SAT & $0.179(0.077)^{*}$ & $0.179(0.077)^{*}$ & \multirow[t]{4}{*}{ Control variable paths } \\
\hline $\mathrm{ACPIR} \rightarrow \mathrm{CIN}$ & $-0.086(0.090)$ & $-0.087(0.090)$ & \\
\hline $\mathrm{ACPIR} \rightarrow \mathrm{NEUT}$ & $0.384(0.094)^{* * *}$ & $0.386(0.094) * * *$ & \\
\hline $\mathrm{ACPIR} \rightarrow \mathrm{ATT}$ & $0.186(0.098)^{\dagger}$ & $0.194(0.096)^{*}$ & \\
\hline SQ corr CQ & $0.474(0.118)^{* * *}$ & $0.474(0.118)^{* * *}$ & \multirow{6}{*}{$\begin{array}{l}\text { Correlations between } \\
\text { exogenous variables }\end{array}$} \\
\hline SE corr CQ & $0.340(0.117)^{* *}$ & $0.340(0.117)^{* *}$ & \\
\hline SE corr SQ & $0.697(0.085)^{* * *}$ & $0.698(0.085) * * *$ & \\
\hline ACPIR corr CQ & $0.066(0.109)$ & $0.066(0.109)$ & \\
\hline ACPIR corr SQ & $0.019(0.101)$ & $0.019(0.101)$ & \\
\hline ACPIR corr SE & $0.058(0.108)$ & $0.058(0.108)$ & \\
\hline $\begin{array}{l}\text { E(ATT4) corr E(ATT2) } \\
\end{array}$ & 0 (fixed) & $0.614(0.153)^{* * *}$ & \multirow{2}{*}{$\begin{array}{l}\text { Correlations between error } \\
\text { terms }\end{array}$} \\
\hline $\mathrm{E}(\mathrm{ATT})$ corr $\mathrm{E}(\mathrm{CIN})$ & $-0.102(0.116)$ & 0 (fixed) & \\
\hline $\mathrm{R}^{2} \mathrm{SAT}$ & $0.807(0.089)^{* * *}$ & $0.812(0.088)^{* * *}$ & \multirow[t]{4}{*}{ Share of variance explained } \\
\hline $\mathrm{R}^{2} \mathrm{CIN}$ & $0.273(0.078)^{* * *}$ & $0.273(0.077) * * *$ & \\
\hline $\mathrm{R}^{2} \mathrm{NEUT}$ & $0.175(0.072)^{*}$ & $0.175(0.071)^{*}$ & \\
\hline $\mathrm{R}^{2} \mathrm{ATT}$ & $0.299(0.102)^{* *}$ & $0.348(0.099) * * *$ & \\
\hline
\end{tabular}

\section{Discussion}

While our current research model did not include measured future behavioral outcomes, especially attitude toward behavior (as in an overall evaluation of performing the behavior) is known as a strong predictor of behavior within various rationality-based theories. In piracy studies employing TPB, attitude is typically the strongest predictor of intention. Neutralization is variedly proposed as influencing either intentions [24], behaviors [23,45], or as a mediator for other factors such as perceived risks and benefits [25] and moral intensity [26]. In this study, we positioned piracy neutralization as an antecedent of attitude toward piracy, because it represents the dissonance reduction phase in the cognitive dissonance sequence. Dissonance reduction efforts will always result in an altered set of cognitions, and attitudes toward piracy are less resistant to change than behaviors.

In summary, four of our seven study hypotheses were supported. First, regarding the nature of the SVOD services themselves, perceived content quality is the main driver of SVOD satisfaction (H1a), and that SVOD satisfaction is positively related to intention to continue using SVOD services $(\mathrm{H} 2)$. Second, the general CDT-derived connection held: piracy neutralization and attitude toward piracy are clearly linked (H4). However, the results indicated only a rather modest link between SVOD perceptions and piracy perceptions through neutralization $(\mathrm{H} 3 b)$.

\subsection{Theoretical implications}

Based on CDT, we predicted that satisfaction with SVOD services would be negatively associated with attitudes toward piracy and lessen the propensity to neutralize, or to agree with neutralizing sentiments. The findings regarding these hypotheses were that SVOD satisfaction had no direct effect on attitude toward piracy, and a small-to-medium effect on piracy neutralization. In other words, the effects of SVOD satisfaction on attitude toward piracy are mediated by dissonance reduction processes.

While both legal and illegal entertainment sources provide similar content, there are key differences in terms of scale and timing of releases. SVOD services cannot offer the same new movies as soon as they hit theatres or even when they are released as Blu-ray, but come with exclusive content, especially in the serial production form, but also increasingly in the movie form. The exclusivity is of course limited to legal services; the content can be acquired through pirate channels very quickly after release, or sometimes before that. Pirate channels will always remain more flexible than a single SVOD service.

We must remember that our SVOD-related questions were framed in terms of a single primarily used service that the users indicated themselves. It is possible that the consumers in our sample did not expect a single SVOD service to be an alternative to piracy, but a legal complement with limited offerings. In this case, the issue might not come down to a choice between SVOD and piracy, but to separate continuance decisions for various SVOD services (and for piracy), each judged based on whether they contribute enough to the current needs and wants for new content. If the consumer is used to pirate content but would prefer a legal alternative if provided, an individual SVOD 
service may be evaluated based on how well the service replaces piracy needs. Still, piracy will remain as an option for accessing content not provided by the SVOD service. If SVOD and piracy are not perceived to be true alternatives in this sense, CDT will not apply in the free choice terms, and perceived SVOD qualities and satisfaction could remain only weakly related to piracy perceptions.

\subsection{Practical implications}

In practice, this study raises doubts about suggestions that pirates could be effectively turned away from their practices by solely improving legal services. Enforcing previously identified important predictive factors such as perceived risks and sanctions [13] should still remain as a part of an effective antipiracy strategy. Between digital video rentals, download stores, and SVOD, legal consumption alternatives are already very broad, but the individual services do not sport very inclusive catalogues. In the current media landscape, all-encompassing individual services seem unrealistic. To minimize the need for pirate channels, subscription fees should be kept as low that they allow for subscription of multiple services.

Other targets to combat against are the neutralizations employed to create tolerance around piracy. The applicability of neutralizations continues to develop with the surrounding perceptions about reality: when neutralizations are successfully discredited, they lose their effectiveness. An example of a nowadays increasingly discredited, but still situationally applicable neutralization is the argument that "there are no legal alternatives to watch it, so I pirated it". If neutralizations are based on objectively false facts ("All artists are rich, thus piracy doesn't hurt them"), they should not persist for long, if they are properly addressed. But, if the neutralizing argument is based on a perceived true problem faced by consumers (e.g., in the past, the notoriously restricted music playback possibilities due to DRM), not much can be done, except to attempt to solve the problem to benefit both consumers and businesses.

\subsection{Limitations and further research}

The data for this study was drawn from an onlinecollected cross-sectional sample, which limits our inferences about causality. This design is also subject to threats from self-selection and method biases. While we took a priori steps to minimize CMB, and the posthoc test results were favorable in light of the recent knowledge [43], we remain cautious and acknowledge that we cannot entirely rule out $\mathrm{CMB}$, because its sources are diverse and complex [46].

One could argue that the price of subscription which was not included in the model - would affect SVOD satisfaction. As the study excluded the more expensive sports subscriptions, the options were quite evenly priced at €8-12/month; price itself would not have differentiated much. However, price perceptions could have additional effects on satisfaction.

Our population of interest, previous and current SVOD users, also constitutes a limitation. Looking at sample mean values, satisfaction and continuance intention scores were high, attitudes toward piracy markedly negative, and the tendency for piracy neutralization low to moderate. We cannot generalize these results to the current non-adopters of SVOD services. As a major difference, their SVOD perceptions would be based only on prior expectations, with no confirmatory experiences underlying assessments of quality and satisfaction. The potential connections between the SVOD non-adopters' perceptions about SVOD services and their piracy perceptions remain a topic for further research.

\section{References}

[1] IFPI, IFPI Digital Music Report 2015 - Charting the Path to Sustainable Growth, International Federation of the Phonographic Industry, http://www.ifpi.org/downloads/Digital-Music-Report-2015. pdf, 2015.

[2] R. LaRose, and J. Kim, "Share, steal, or buy? A social cognitive perspective of music downloading", CyberPsychology \& Behavior, 10 (2), 2007, pp. 267-277.

[3] J.R. Coyle, S.J. Gould, P. Gupta, and R. Gupta, "“To buy or to pirate": The matrix of music consumers' acquisitionmode decision-making", J. Bus. Research, 62 (10), 2009, pp. 1031-1037.

[4] K. Borja, S. Dieringer, and J. Daw, "The effect of music streaming services on music piracy among college students", Comput. Hum. Behav., 45, 2015, pp. 69-76.

[5] K. Borja, and S. Dieringer, "Streaming or stealing? The complementary features between music streaming and music piracy", Journal of Retailing and Consumer Services, 32, 2016, pp. 86-95.

[6] G.M. Sykes, and D. Matza, "Techniques of neutralization: A theory of delinquency", Am. Sociol. Rev., 22 (6), 1957, pp. 664-670.

[7] L. Festinger, A Theory of Cognitive Dissonance, Stanford University Press, Stanford, California, 1962.

[8] R.L. Oliver, "A cognitive model of the antecedents and consequences of satisfaction decisions", J. Market. Res., 17, 1980, pp. 460-469.

[9] A. Bhattacherjee, "Understanding information systems continuance: an expectation-confirmation model", MIS quarterly, 25 (3), 2001, pp. 351-370.

[10] M. Fishbein, I. Ajzen, Belief, Attitude, Intention and Behavior: An Introduction to Theory and Research, AddisonWesley, Reading, MA, 1975. 
[11] I. Ajzen, From Intentions to Actions: A Theory of Planned Behavior, In Action Control (pp. 11-39), Springer Berlin Heidelberg, 1985.

[12] M. Fishbein, I. Ajzen, Prediction and Change of Behavior: The Reasoned Action Approach, Psychology Press, New York, 2010.

[13] P.B. Lowry, J. Zhang, and T. Wu, "Nature or nurture? A meta-analysis of the factors that maximize the prediction of digital piracy by using social cognitive theory as a framework", Comput. Hum. Behav., 68, 2017, pp. 104-120.

[14] T.P. Cronan, and S. Al-Rafee, "Factors that influence the intention to pirate software and media", J. Bus. Ethics, 78 (4), 2008, pp. 527-545.

[15] C. Yoon, "Theory of planned behavior and ethics theory in digital piracy: An integrated model", J. Bus. Ethics, 100 (3), 2011, pp. 405-417.

[16] I. Redondo, and J. Charron, "The payment dilemma in movie and music downloads: An explanation through cognitive dissonance theory", Comput. Hum. Behav., 29 (5), 2013, pp. 2037-2046.

[17] P. Odou, and G. Bonnin, "Consumers' neutralization strategies to counter normative pressure: The case of illegal downloading", Recherche et Applications en Marketing (English Edition), 29 (1), 2014, pp. 103-121.

[18] J. Riekkinen, "Dissonance and Neutralization of Subscription Streaming Era Digital Music Piracy: An Initial Exploration", PACIS 2016 Proceedings, 2016, paper 251.

[19] R. Willison, and M. Warkentin, "Beyond deterrence: An expanded view of employee computer abuse", MIS quarterly, 37 (1), 2013, pp. 1-20.

[20] S. Maruna, and H. Copes, "What have we learned from five decades of neutralization research?", Crime and justice, 32, 2005, pp. 221-320.

[21] J.R. Ingram, and S. Hinduja, "Neutralizing music piracy: An empirical examination", Deviant Behav., 29 (4), 2008, pp. 334-366.

[22] R.G. Morris, and G.E. Higgins, "Neutralizing Potential and Self-Reported Digital Piracy: A Multitheoretical Exploration Among College Undergraduates", Crim. Justice Rev., 34 (2), 2009, pp. 173-195.

[23] G.E. Higgins, S.E. Wolfe, and C.D. Marcum, "Music piracy and neutralization: a preliminary trajectory analysis from short-term longitudinal data", International Journal of Cyber Criminology, 2 (2), 2008, pp. 324-336.

[24] M. Siponen, A. Vance, and R. Willison, "New insights into the problem of software piracy: The effects of neutralization, shame, and moral beliefs", Information \& Management, 49 (7-8), 2012, pp. 334-341.

[25] I. Vida, M. Kos Koklic, M. Kukar-Kinney, and E. Penz, "Predicting consumer digital piracy behavior: The role of rationalization and perceived consequences", J. Res. in Interactive Marketing, 6 (4), 2012, pp. 298-313.

[26] M. Kos Koklic, M. Kukar-Kinney, and I. Vida, "ThreeLevel Mechanism of Consumer Digital Piracy: Development and Cross-Cultural Validation", J. Bus. Ethics, 134 (1), 2016, pp. $15-27$.

[27] J. Cooper, Cognitive Dissonance: 50 Years of a Classic Theory, Sage, 2007.

[28] D. Hausknecht, J.C. Sweeney, G.N. Soutar, and L.W. Johnson, ""After I had made the decision, I...": Toward a scale to measure cognitive dissonance", Journal of Consumer
Satisfaction, Dissatisfaction and Complaining Behavior, 11, 1998, pp. 119-127.

[29] R.L. Oliver, "Effect of expectation and disconfirmation on postexposure product evaluations: An alternative interpretation", J. Appl. Psychol., 62 (4), 1977, pp. 480-486.

[30] F.D. Davis, "Perceived usefulness, perceived ease of use, and user acceptance of information technology", MIS quarterly, 13 (3), 1989, pp. 319-340.

[31] D.H. Shin, "An empirical investigation of a modified technology acceptance model of IPTV", Behaviour \& Information Technology, 28 (4), 2009, pp. 361-372.

[32] D.H. Shin, "Determinants of customer acceptance of multi-service network: An implication for IP-based technologies", Information \& Management, 46 (1), 2009, pp. 16-22.

[33] T. Ingham, Frank Ocean's Blonde has been illegally downloaded 750,000 times in less than a week, http://www.musicbusinessworldwide.com/frank-oceans-

blonde-has-been-illegally-downloaded-750000-times-in-lessthan-a-week/, 2016.

[34] W.H. DeLone, and E.R. McLean, "Information systems success: The quest for the dependent variable", Information Systems Research, 3 (1), 1992, pp. 60-95.

[35] J.H. Cheong, and M. Park, "Mobile internet acceptance in Korea", Internet research, 15 (2), 2005, pp. 125-140.

[36] J. Poort, and J. Weda, "Elvis Is Returning to the Building: Understanding a Decline in Unauthorized File Sharing", J. Media Econ., 28 (2), 2015, pp. 63-83.

[37] J.W. Brehm, "Postdecision changes in the desirability of alternatives", The Journal of Abnormal and Social Psychology, 52 (3), 1956, pp. 384-389.

[38] J.C. Anderson, and D.W. Gerbing, "Structural equation modeling in practice: A review and recommended two-step approach", Psychol. Bull., 103 (3), 1988, pp. 411-423.

[39] S. Hinduja, "Neutralization theory and online software piracy: An empirical analysis", Ethics and Information Technology, 9 (3), 2007, pp. 187-204.

[40] P. Cromwell, and Q. Thurman, "The devil made me do it: Use of neutralizations by shoplifters", Deviant Behav., 24 (6), 2003, pp. 535-550.

[41] C. Fornell, and D.F. Larcker, "Evaluating structural equation models with unobservable variables and measurement error", J. Market. Res., 18, 1981, pp. 39-50.

[42] P.M. Podsakoff, S.B. MacKenzie, J. Lee, and N.P. Podsakoff, "Common method biases in behavioral research: a critical review of the literature and recommended remedies", J. Appl. Psychol., 88 (5), 2003, pp. 879-903.

[43] C.M. Fuller, M.J. Simmering, G. Atinc, Y. Atinc, and B.J. Babin, "Common methods variance detection in business research", J. Bus. Research, 69 (8), 2016, pp. 3192-3198.

[44] A. Satorra, and P.M. Bentler, "A scaled difference chisquare test statistic for moment structure analysis", Psychometrika, 66 (4), 2001, pp. 507-514.

[45] A. Chatzidakis, S. Hibbert, and A.P. Smith, "Why people don't take their concerns about fair trade to the supermarket: The role of neutralisation", J. Bus. Ethics, 74 (1), 2007, pp. 89-100.

[46] V.D.R. Guide, and M. Ketokivi, "Notes from the Editors: Redefining some methodological criteria for the journal", J. Oper. Manage., (37), 2015, pp. v-viii. 